\title{
Phytochemical Aspects, Cytotoxicity and Antimicrobial Activity of the Methanolic Extract of Tropical Fruit Pulps on Clinical Isolates of Escherichia coli
}

\author{
Lorena Kimberly Silva Alcântara ${ }^{1,2, \uparrow}$ (i) , Luiz Felipe Carreiro Machado 1,2,†(i), Isabela Penna \\ Ceravolo $^{3}$, (i) Renan Martins dos Santos ${ }^{1,2,4}$ (i), Marcus Vinícius Dias-Souza ${ }^{1,2,4, * \text { (i) }}$ \\ 1 PharmBSc Program, Pitágoras College, 789 Carlos Chagas Av., Ipatinga, MG, Zip: 35162-359, Brazil \\ 2 Reference Center for Drug Information (CRIMED), Pitágoras College, 789 Carlos Chagas Av., Ipatinga, MG, Zip: $35162-$ \\ 359, Brazil \\ 3 René Rachou Institute, 1715 Augusto de Lima Av., Belo Horizonte, MG, Zip: 30190-002, Brazil \\ $4 \quad$ Integrated Pharmacology and Drug Interactions Research Group (GPqFAR), Brazil \\ * Correspondence: souzamvd@gmail.com; \\ $\dagger$ Authors contributed equally to this work
}

Scopus Author ID 56543795600

Received: 3.07.2020; Revised: 19.07.2020; Accepted: 20.07.2020; Published: 22.07.2020

\begin{abstract}
Escherichia coli is naturally present at the gastrointestinal tract of humans, but is also involved in diseases such as urinary tract infection. The current scenario of bacterial resistance to antimicrobials raises the demand for new drugs, and natural products represent interesting sources of bioactive compounds. Here we investigated the cytotoxicity and antimicrobial potential of $80 \%$ methanolic extracts of Spondias tuberosa (umbu), Spondias purpurea (seriguela), and Theobroma grandiflorum (cupuaçu) fruit juice pulps against clinical isolates of uropathogenic E. coli. Phytochemical aspects of the pulps were elucidated, and their antioxidant properties were analyzed. The minimal inhibitory concentration (MIC) of the extracts was of $500 \mu \mathrm{g} / \mathrm{mL}$, and no toxicity was observed against BGM cells. Vitamin C and total carbohydrates were not in accordance to the levels determined in the legislation. We used HPLC to confirm the presence of flavonoids. To the best of our knowledge, this is the first report of the antimicrobial potential of these fruit pulps. Our data open doors for more studies with chromatographic fractions and isolated flavonoids from these pulps.
\end{abstract}

Keywords: plant extract; uropathogenic E. coli; antimicrobial; umbu; seriguela; cupuaçu.

(C) 2020 by the authors. This article is an open-access article distributed under the terms and conditions of the Creative Commons Attribution (CC BY) license (https://creativecommons.org/licenses/by/4.0/).

\section{Introduction}

Escherichia coli is a relevant Gram-negative commensal microorganism actively involved in colonizing the gastrointestinal tract of humans, precluding the entry of pathogenic species. However, E. coli may reach other body sites and behave as a pathogen, causing diseases such as urinary tract infection (UTI) [1-3]. UTI is a common bacterial infection, especially in women, and results in decreased quality of life because of the symptoms, which include dysuria, increased urinary frequency, suprapubic pain, and hematuria $[2,4,5]$. Uropathogenic E. coli (UPEC) strains are mostly detected in uncomplicated cystitis cases, but might also be found at the kidneys, bladder, and even at the blood on complex cases [5-7].

The treatment of UTI is largely dependent on antimicrobial drugs, but bacterial resistance makes it technically difficult $[2,8]$. Several genetically regulated mechanisms have been described in UPEC, including efflux pumps and $\beta$-lactamases $[6,8-10]$. A recent WHO 
Global Surveillance of Antimicrobial Resistance reported high rates of E. coli resistance to third-generation cephalosporins and fluoroquinolones, the standard choices for the treatment [11]. Incorrect prescription and use of antimicrobials are widely recognized as the main causes of bacterial resistance $[5,6]$. Thus, beyond the education of prescribers and patients on this topic, there is an urgent need for new antimicrobial drugs. Plant-derived metabolites are promising compounds in the antimicrobial research context. Reports on resistance to natural products are rare, and many of them present broad-spectrum activity [12]. Roots, stems, and leaves of plants, which are not always edible, are commonly explored for phytochemical and pharmacological studies with microorganisms.

Our group has been prospecting antimicrobial extracts of edible parts of plants such as fruits, which have extensive culinary and cosmetic use but are far less investigated for biological properties such as antimicrobial, antioxidant, and wound healing. Here we report the cytotoxicity of the methanolic extracts of Spondias tuberosa (umbu), Spondias purpurea (siriguela), and Theobroma grandiflorum (cupuaçu) fruit juice pulps, and their antimicrobial activity on UPEC strains. Their pulps are widely used for preparing juices, ice-cream, and other food preparations that are economically important in several Brazilian cities, especially in the northeast (siriguela/umbu) and north (cupuaçu) regions [13]. Non-edible parts of these plants are popularly used on the treatment of inflammatory and infectious diseases, but no investigation has been conducted so far with the fruit pulps. Phytochemical analyses indicated the presence of tannins and flavonoids, and a comparative analysis of their antioxidant potential was conducted. To the best of our knowledge, such evidence are being provided for the first time, making our work even more relevant concerning the treatment of UTI.

\section{Materials and Methods}

\subsection{Pulps samples.}

The pulp samples used in this study belong to a brand widely sold in Brazil. Samples were purchased (10 units each) from local markets at Minas Gerais State and consisted of integral frozen pulps in vacuum-sealed plastic containers, which require adding water and culinary sugar prior to consumption, as recommended by the manufacturer. Products were of the same batch code. All pulps were stored at $-20{ }^{\circ} \mathrm{C}$ until used, and defrosted in a refrigerator prior to the tests.

\subsection{Biochemical assays with the whole pulps.}

\subsubsection{Carbohydrates.}

Total carbohydrates were determined in each sample using the phenol-sulphuric method [14]. A calibration curve was prepared using glucose as a standard.

\subsubsection{Vitamin C quantitative detection.}

Vitamin C (ascorbic acid) content was determined in triplicate, as previously described [15]. A total of $35 \mathrm{~mL}$ of starch-sulphuric acid solution was added to $25 \mathrm{~g}$ of each pulp and mixed. The solution was titrated with $0.1 \mathrm{M}$ iodine solution while stirring until the first stable blue color was seen. 


\subsection{Preparation of methanolic extracts.}

The extracts were prepared at home temperature with $80 \%$ methanol solution through magnetic stirring at maximum speed for $24 \mathrm{~h}$. The solution was then rotavaporized to dryness under vacuum at $50{ }^{\circ} \mathrm{C}$. The final product was weighed and stored at $4{ }^{\circ} \mathrm{C}$ until used.

\subsection{Qualitative phytochemical screening.}

The extracts were analyzed through classical methods [16]. Shinoda method for flavonoids was conducted as follows: the dried extracts were suspended in enough quantity of water and mixed with fragments of magnesium ribbon. $\mathrm{HCl}$ was dropped until the pink color was seen, indicating a positive result. For tannins, the suspended extracts were boiled in water for 10 minutes, filtrated in Whatman paper (n\#10), and $0.1 \%$ ferric chloride was dropped on the filtrate. A brownish-green or a blue-black color indicated a positive result. For saponins, olive oil was added to the filtrate and agitated using a vortex at maximum speed. The formation of an emulsion showed a positive result.

\subsection{Antioxidant activity.}

The antioxidant activity of the extracts at $1 \mathrm{mg} / \mathrm{mL}$ was analyzed in duplicate by the $\beta$ carotene bleaching assay, as described [15]. The antioxidant chloroform solution was prepared with $\beta$-carotene, linoleic acid and Tween 40 , and readings were taken in a spectrophotometer at $470 \mathrm{~nm}$ at $0,15,30,45$, and 60 min intervals.

\subsection{High-Performance Liquid Chromatography coupled to diode array (HPLC-DAD) analysis.}

We conducted HPLC analysis to detect polyphenols in the samples following the extract preparation method and equipment program as described by our group [17]. Aliquots of $20 \mu \mathrm{L}$ of the extracts were injected in a C18 column (Shim-pack ODS) of a SPD 20A HPLCDAD system (Shimadzu), and fractions were separated with gradient elution consisting in water and methanol at a flow rate of $0.5 \mathrm{~mL} / \mathrm{min}$. Polyphenols were detected at $254 \mathrm{~nm}$.

\subsection{Bacterial strains.}

Clinical UPEC isolates were from the collection of the clinical laboratory of Pitágoras College. The strains were cultured in nutrient broth (Difco) overnight and were tested for identity confirmation using VITEK 2 system (version R04.02, BioMérieux SA, Marcy-l'Étoile, France) with identification cards, following the manufacturer's instructions.

\subsection{Minimal inhibitory concentration (MIC) assay.}

The MIC of the extracts was determined in untreated sterile 96-well polystyrene microtiter plates using an adapted CLSI protocol published by our group [18]. Bacterial cultures were prepared in Mueller Hinton broth (Difco, Becton Dickinson, USA) in 1 McFarland scale by adjusting the optical density to 1 at $600 \mathrm{~nm}$ wavelength. The wells received each of the extracts serially diluted, creating a final concentration of the bacterial inoculum equal to $0.5 \mathrm{McF}$ arland scale and final concentrations of drugs ranging from $1 \mathrm{mg} / \mathrm{mL}$ to 7.8 $\mu \mathrm{g} / \mathrm{mL}$ (final volume of $200 \mu \mathrm{L}$ ). MIC was established as the lowest concentration in which 
resazurin $(0.1 \mathrm{~g} / \mathrm{L})$ staining was unaltered (no color modification from blue to pink) in all strains. The extracts were used as a negative control.

\subsection{Cytotoxicity of the extracts.}

The cytotoxic effect of the extracts was tested in triplicate using immortalized fibroblast-like BGM cells, as described previously [17]. The cells were treated with $20 \mu \mathrm{L}$ of each extract in concentrations ranging from 500 to $7.81 \mu \mathrm{g} / \mathrm{mL}$. The plates were incubated for $24 \mathrm{~h}$. Cell viability was assessed by resazurin staining $(0.1 \mathrm{~g} / \mathrm{L})$. The plates were then incubated for four $\mathrm{h}$, and readings were taken in a fluorimetric microplate reader $\left(\lambda_{\mathrm{ex}} 570 \mathrm{~nm}, \lambda_{\mathrm{em}} 590 \mathrm{~nm}\right)$. Untreated cells were used as the control group.

\section{Results and Discussion}

\subsection{Biochemical analyzes, antimicrobial activity, and cytotoxicity.}

Vitamin C was not detected in the pulps, and the total carbohydrate levels were lower than the ranges determined by the Brazilian laws (Table 1). All the extracts were effective against the clinical isolates of $E$. coli. The extracts were not cytotoxic to BGM cells: cell viability was not statistically different from the untreated control (data not shown).

Table 1. Antimicrobial and biochemical parameters of the fruit pulps.

\begin{tabular}{c|c|c|c} 
Parameter & T. grandiflorum & S. purpurea & S. tuberosa \\
\hline MIC $^{\alpha}$ & $500 \mu \mathrm{g} / \mathrm{mL}$ & $500 \mu \mathrm{g} / \mathrm{mL}$ & $500 \mu \mathrm{g} / \mathrm{mL}$ \\
\hline Vitamin C & $\mathrm{ND}$ & $\mathrm{ND}$ & $\mathrm{ND}$ \\
\hline Reference Value & $\mathrm{X}>18 \mathrm{mg} / 100 \mathrm{~g}$ & $\Delta$ & $\mathrm{X}>12.9 \mathrm{mg} / 100 \mathrm{~g}$ \\
\hline Carbohydrates & $3.74 \mathrm{~g} / 100 \mathrm{~g}$ & $5 \mathrm{~g} / 100 \mathrm{~g}$ & $\mathrm{ND}$ \\
\hline Reference Value & $\mathrm{X}>6 \mathrm{~g} / 100 \mathrm{~g}$ & $\Delta$ & $\mathrm{X}>2.4 \mathrm{~g} / 100 \mathrm{~g}$
\end{tabular}

$\Delta-$ Reference values for $S$. purpurea are not available in the current legislation. ND: not detected. MIC: Minimal inhibitory concentration. $\alpha$ : Values for all bacterial strains.

\subsection{Phytochemical profile of the pulps.}

The qualitative tests indicated the presence of flavonoids and tannins in all samples, but saponins were not detected in any of the pulps. HPLC analysis confirmed the presence of polyphenols on the samples at $254 \mathrm{~nm}$ (Fig.1). The identification of the flavonoids is being conducted for further studies.

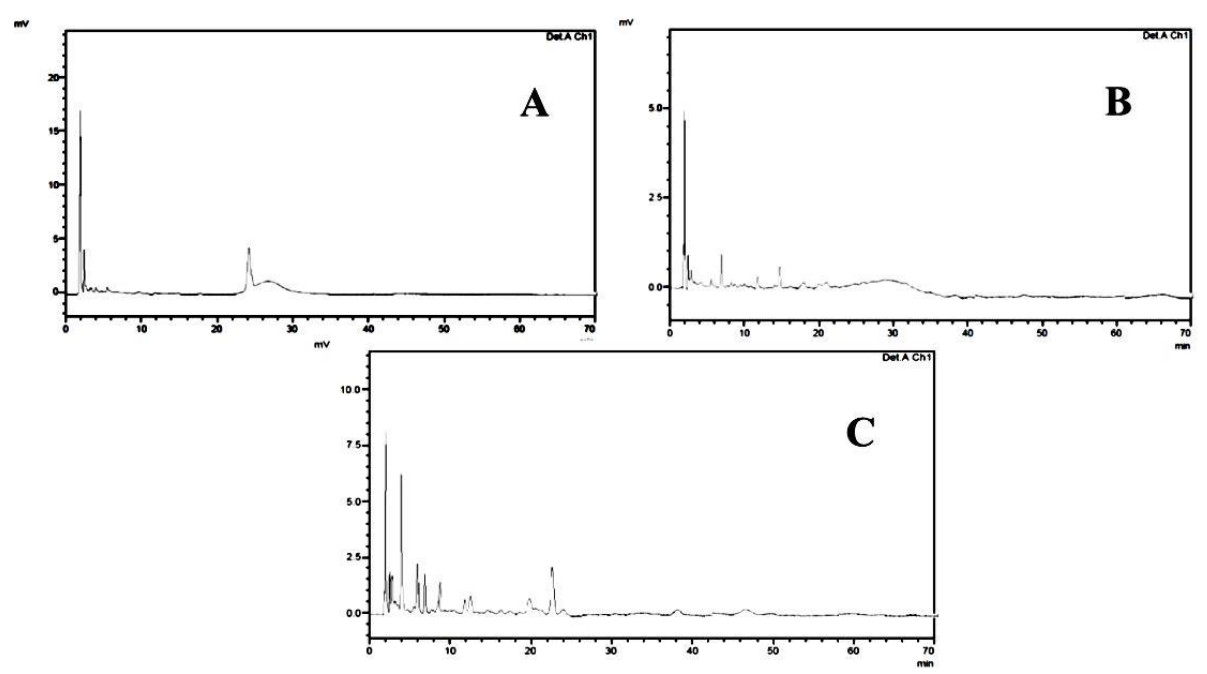

Figure 1. HPLC chromatograms of the extracts. A: T. grandiflorum, B: S. purpurea, C: S. tuberosa. 


\subsection{Antioxidant activity.}

The extracts presented interesting antioxidant activity (Fig. 2), and all were statistically significant when compared to the untreated $\beta$-carotene solution used as control $(\mathrm{p}<0.05) . T$. grandiflorum presented $48.21 \%$ of antioxidant protection, whereas S. tuberosa and S. purpurea presented $67.64 \%$ and $68.17 \%$ of antioxidant protection, respectively. Differences between $S$. tuberosa and $S$. purpurea results were not statistically significant, although their protective effect was superior to $T$. grandiflorum ( $\mathrm{p}>0.05$ ).

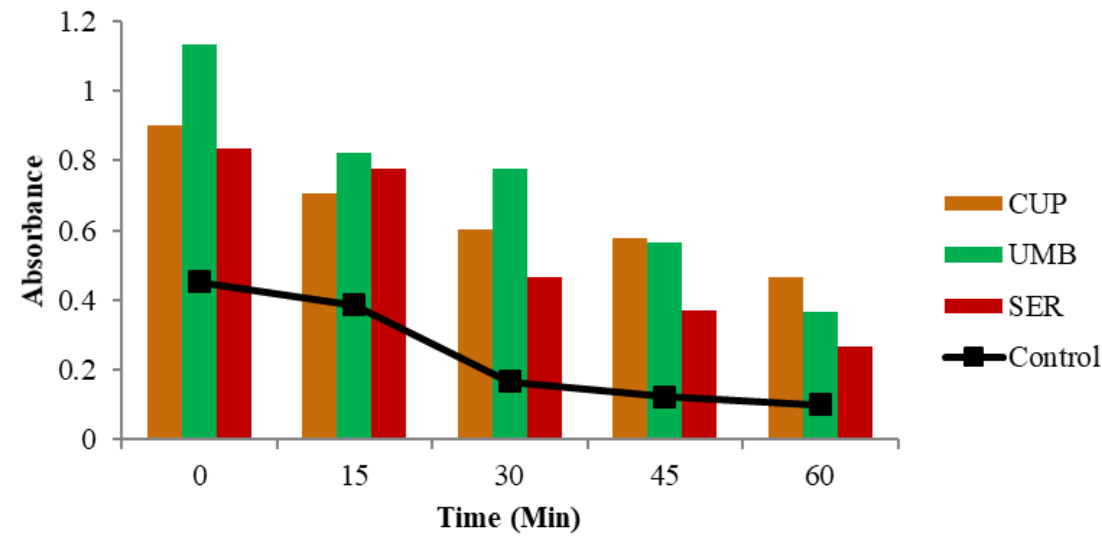

Figure 2. Antioxidant potential of the pulp extracts. CUP: T. ganrdifolium sample (cupuaçu); UMB: S. tuberosa (umbu); SER: S. purpurea (seriguela).

\subsection{Discussion.}

S. tuberosa provides its fruits in dry seasons under considerable salt and hydric stress [19]. The pulp is rich in flavonoids, minerals, ascorbic acid, and carotenoids, and its exotic flavor reached from juices to ice-creams $[19,20]$. T. grandiflorum, as the name suggests, is genetically close to Theobroma cacao (chocolate), albeit there are phytochemical differences [21]. A chocolate-like product can be prepared using T. grandiflorum seeds [22]. $T$. grandiflorum is mostly explored for juice, ice-cream, and butter, used in both food and cosmetic industries [21, 22]. S. purpurea is rich in phenolic molecules and is traditionally used for gastrointestinal disorders and parasitic infections [23]. Fruit pulps, however, remain poorly explored. To the best of our knowledge, this is the first study on the antimicrobial activity of S. tuberosa, T. grandiflorum, and S. purpurea fruit pulps hydromethanolic extract. The leaf and stem bark extracts of these plants are traditionally used for several conditions such as diarrhea and other intestinal disorders, diabetes, and infectious diseases, and some evidence has suggested their antimicrobial potential [19-25]. The juices of these fruits are rich in several phytochemical molecules, and thus, we hypothesized that the pulps could present antimicrobial potential as well.

The antimicrobial activity of the $80 \%$ methanolic extracts of the fruit pulps was assessed using broth microdilution, and a $500 \mu \mathrm{g} / \mathrm{mL}$ MIC was found for all extracts. Although some strains were susceptible to the extracts in lower concentrations (data not shown), MIC values were analyzed considering all the microorganisms. As the clinical isolates are from different patients with different backgrounds concerning the immune system and the use of antimicrobial drugs, some variability on MIC values amidst the isolates were expected. Previous studies of our group with fruit pulp-based extracts reached lower MIC values, such as for cashew apple and açaí pulps $[15,17]$. The nutritional quality of the pulps is probably the 
most plausible explanation for these differences and can be influenced by several factors such as soil nutrition, time of harvesting, and industrial processing steps. These factors, especially the last one, might also explain the unexpected absence of vitamin $\mathrm{C}$, an important immunomodulatory and antioxidant nutrient.

One might ask why we did not perform minimal bactericidal concentration (MBC) or minimal biofilm eradication concentration (MBEC) tests. Previous findings from our group are in agreement with the observation of others that MIC and MBC values of crude phytoextracts are rarely equal or close, suggesting a bacteriostatic profile [26]. A possible explanation is that bacteria may use harmless phytomolecules as carbon and nitrogen sources to keep growing, in spite of the presence of antimicrobial secondary metabolites as tannins and flavonoids.

We conducted an MBC experiment, but the highest concentration of the extracts (1000 $\mu \mathrm{g} / \mathrm{mL}$ ) was ineffective in inhibiting bacterial growth on agar plates (data not shown). MBEC can be up to 1000 times higher than MIC values [15, 17]. Therefore, an antibiofilm activity of the crude extracts could not be expected. However, preliminary antimicrobial experiments conducted at our laboratory with chromatographic fractions, which can concentrate on structurally similar secondary metabolites, resulted in considerably lower MIC values [Alcântara et al., unpublished data]. These findings open doors for more studies with the pulps.

The extracts were efficient antioxidants. The presence of phytomolecules such as flavonoids and tannins helps to explain this result, as confirmed by HPLC (Fig.1). Carbohydrate levels were unexpectedly low in all pulps (Table 1), and at least two hypotheses may explain this result. First, the maturation level of the fruit used for manufacturing was inadequate. Old fruits present lower levels of carbohydrates, as well as total acidity [27]. Second, the pulps could have been prepared with an increased proportion of water, leading to a final product diluted to some extent. This may have affected vitamin $\mathrm{C}$ levels as well.

Most of the studies on antimicrobial properties of natural herbal products explore leaves and stem barks extracts, generally following ethnopharmacological data [12, 13]. Nevertheless, leaves and stem barks may have cytotoxic effects in fibroblast-like cells due to the presence of secondary metabolites. The extracts had no toxic effect on BGM cells in our tests. Such tests help to predict adverse reactions resulting from the use of the tested items as drugs. Exploring edible fruit as sources of antimicrobial compounds can be an interesting pathway, as the presence of toxic secondary metabolites is unlikely $[23,27]$.

\section{Conclusions}

The three pulp extracts were effective against clinical isolates of UPEC, and more studies with chromatographic fractions are being conducted in order to reach even lower MIC values. This study, nevertheless, is not without limitations. It is possible that artisanal pulps of fresh fruit could provide lower MIC values, as the manufacturing processes can impact on the level of bioactive molecules. Moreover, in vivo studies with animal models of urinary infection are necessary to investigate the antimicrobial potential of the extracts considering the hepatic metabolism and the immune system. These limitations, however, has no implication on our measuring of the antimicrobial activity of the extracts on UPEC strains.

\section{Funding}

This study was funded by grants from Pitágoras College provided to RMDS and MVDS. 


\section{Acknowledgments}

We are thankful to Cleiton Dias, PharmBSc, for the assistance on the preparation of the extracts.

\section{Conflicts of Interest}

The authors declare no conflict of interest.

\section{References}

1. Esmaeel, N.E.; Gerges, M.A.; Hosny, T.A.; Ali, A.R.; Gebriel, M.G. Detection of Chromosomal and Plasmid-Mediated Quinolone Resistance Among Escherichia coli Isolated from Urinary Tract Infection Cases; Zagazig University Hospitals, Egypt. Infection and Drug Resistance 2020, 13, 413-421, https://doi.org/10.2147/IDR.S240013.

2. Hreha, T.N.; Collins, C.A.; Daugherty, A.L.; Twentyman, J.; Paluri, N.; Hunstad, D.A. TGF $\beta 1$ orchestrates renal fibrosis following Escherichia coli pyelonephritis. Physiological Reports 2020, 8, https://doi.org/10.14814/phy2.14401.

3. Sun, J.; Du, L.; Yan, L.; Dai, W.; Wang, Z.; Xu, X. Eight-Year Surveillance of Uropathogenic Escherichia coli in Southwest China. Infection and drug resistance 2020, 13, 1197-1202, https://doi.org/10.2147/IDR.S250775.

4. Halaji, M.; Shahidi, S.; Atapour, A.; Ataei, B.; Feizi, A.: Havaei, S.A. Characterization of ExtendedSpectrum $\beta$-Lactamase-Producing Uropathogenic Escherichia coli Among Iranian Kidney Transplant Patients. Infection and drug resistance 2020, 13, 1429-1437, https://doi.org/10.2147/IDR.S248572.

5. Naziri, Z.; Derakhshandeh, A.; Soltani Borchaloee, A.; Poormaleknia, M.; Azimzadeh, N. Treatment Failure in Urinary Tract Infections: A Warning Witness for Virulent Multi-Drug Resistant ESBL- Producing Escherichia coli. Infection and drug resistance 2020, 13, 1839-1850, https://doi.org/10.2147/IDR.S256131.

6. Thapa Shrestha, U.; Shrestha, S.; Adhikari, N.; Rijal, K. R.; Shrestha, B.; Adhikari, B.; Banjara, M.R.; Ghimire, P. Plasmid Profiling and Occurrence of $\beta$-Lactamase Enzymes in Multidrug-Resistant Uropathogenic Escherichia coli in Kathmandu, Nepal. Infection and drug resistance 2020, 13, 1905-1917, https://doi.org/10.2147/IDR.S250591.

7. Forsyth, V.S.; Himpsl, S.D.; Smith, S.N.; Sarkissian, C.A.; Mike, L.A.; Stocki, J.A.; Sintsova, A.; Alteri, C.J.; Mobley, H. Optimization of an Experimental Vaccine To Prevent Escherichia coli Urinary Tract Infection. mBio 2020, 11, e00555-20, https://doi.org/10.1128/mBio.00555-20.

8. Mahmoud, N.E.; Altayb, H.N.; Gurashi, R.M. Detection of Carbapenem-Resistant Genes in Escherichia coli Isolated from Drinking Water in Khartoum, Sudan. Journal of environmental and public health 2020, 2020, https://doi.org/10.1155/2020/2571293.

9. Gil-Gil, T.; Laborda, P.; Sanz-García, F.; Hernando-Amado, S.; Blanco, P.; Martínez, J.L. Antimicrobial resistance: A multifaceted problem with multipronged solutions. Microbiology Open 2019, 8, https://doi.org/10.1002/mbo3.945.

10. Chernov, V.M.; Chernova, O.A.; Mouzykantov, A.A.; Lopukhov, L.L.; Aminov, R.I. Omics of antimicrobials and antimicrobial resistance. Expert opinion on drug discovery 2019, 14, 455-468, https://doi.org/10.1080/17460441.2019.1588880.

11. Chokshi, A.; Sifri, Z.; Cennimo, D.; Horng, H. Global Contributors to Antibiotic Resistance. Journal of global infectious diseases 2019, 11, 36-42, https://doi.org/10.4103/jgid.jgid_110_18.

12. Joshi, B.; Panda, S.K.; Jouneghani, R.S.; Liu, M.; Parajuli, N.; Leyssen, P.; Neyts, J.; Luyten, W. Antibacterial, Antifungal, Antiviral, and Anthelmintic Activities of Medicinal Plants of Nepal Selected Based on Ethnobotanical Evidence. Evidence-based complementary and alternative medicine: eCAM 2020, 2020, https://doi.org/10.1155/2020/1043471.

13. Valli, M.; Bolzani, V.S. Natural Products: Perspectives and Challenges for use of Brazilian Plant Species in the Bioeconomy. Anais da Academia Brasileira de Ciencias 2019, 91, https://doi.org/10.1590/00013765201920190208.

14. Dubois, M.; Gilles, K.A.; Hamilton, J.K.; Rebers, P.A.; Smith, F. Colorimetric method for determination of sugars and related substances. Analytical Chemistry 1956, 28, 350-356, https://doi.org/10.1021/ac60111a017.

15. Dias-Souza, M.V.; Dos Santos, R.M.; de Siqueira, E.P.; Ferreira-Marçal, P.H. Antibiofilm activity of cashew juice pulp against Staphylococcus aureus, high performance liquid chromatography/diode array detection and gas chromatography-mass spectrometry analyses, and interference on antimicrobial drugs. Journal of food and drug analysis 2017, 25,589-596, https://doi.org/10.1016/j.jfda.2016.07.009

16. Trease, G.E.; Evans, W.C. Pharmacognosy. 11th ed., Bailliere Tindall, London, 1989.

17. Dias-Souza, M.V.; Dos Santos, R.M.; Cerávolo, I.P.; Cosenza, G.; Ferreira Marçal, P.H.; Figueiredo, F. Euterpe oleracea pulp extract: Chemical analyses, antibiofilm activity against Staphylococcus aureus, 
cytotoxicity and interference on the activity of antimicrobial drugs. Microbial pathogenesis 2018, 114, 2935, https://doi.org/10.1016/j.micpath.2017.11.006.

18. Dias-Souza, M.V.; Andrade, S.; Aguiar, A.P.; Monteiro, Andrea S. Evaluation of Antimicrobial and Antibiofilm activities of Anacardium occidentale stem bark extract. Journal of Natural Products 2013, 26, 198205, 2013.

19. Cordeiro, B.; Carvalho Junior, A.R.; Santos, J.; Araújo, A.D.; Silva, A.G.; Correia, M.; Silva, M.V.; Napoleão, T.H.; Silva, L.; Santos, N.; Paiva, P. Anticryptococcal activity of hexane extract from Spondias tuberosa Arruda and associated cellular events. Journal de mycologie medicale 2020, 30, https://doi.org/10.1016/j.mycmed.2020.100965.

20. Santos, V.; Almeida, C. The complete chloroplast genome sequences of three Spondias species reveal close relationship among the species. Genetics and molecular biology 2019, 42, 132-138, https://doi.org/10.1590/1678-4685-GMB-2017-0265.

21. Santana Silva, R.J.; Alves, R.M.; Peres Gramacho, K.; Marcellino, L.H.; Micheli, F. Involvement of structurally distinct cupuassu chitinases and osmotin in plant resistance to the fungus Moniliophthora perniciosa. Plant Physiology and Biochemistry 2020, 148, 142-151, https://doi.org/10.1016/j.plaphy.2020.01.009.

22. Ramos, S.; Salazar, M., Nascimento, L., Carazzolle, M., Pereira, G., Delforno, T., Nascimento, M., de Aleluia, T., Celeghini, R., \& Efraim, P. Influence of pulp on the microbial diversity during cupuassu fermentation. International Journal of Food Microbiology 2020, 318 , https://doi.org/10.1016/j.ijfoodmicro.2019.108465.

23. Melo, P.; Nunes, J.C.; Otoni, C. G.; Aouada, F.A.; de Moura, M.R. Combining Cupuassu (Theobroma grandiflorum) Puree, Pectin, and Chitosan Nanoparticles into Novel Edible Films for Food Packaging Applications. Journal of Food Science 2019, 84, 2228-2233, https://doi.org/10.1111/1750-3841.14685.

24. Muñiz, A.; Garcia, E.; Gonzalez, D.; Zuñiga, L. Antioxidant Activity and In Vitro Antiglycation of the Fruit of Spondias purpurea. Evidence-based complementary and alternative medicine 2018, 2018, https://doi.org/10.1155/2018/5613704.

25. Cristóbal-Pérez, E.J.; Fuchs, E.J.; Olivares-Pinto, U.; Quesada, M. Janzen-Connell effects shape gene flow patterns and realized fitness in the tropical dioecious tree Spondias purpurea (ANACARDIACEAE). Scientific Reports 2020, 10, https://doi.org/10.1038/s41598-020-61394-4.

26. Levison, M.E.; Levison, J.H. Pharmacokinetics and pharmacodynamics of antibacterial agents. Infectious disease clinics of North America 2009, 23, 791-815, https://doi.org/10.1016/j.idc.2009.06.008.

27. Marçal, P.H.F.; Dias-Souza, M.V.; Vilella, E.G.; Luz, L.M.; Pereira, M.K. Qualidade Físico-Química, Microbiológica e Microscópica de Polpas de Frutas Congeladas Comercializadas no Município de Governador Valadares, MG. Nova: Revista Científica 2014, 2, 1-10.

28. Biswal, P.; Pal, A.; Das, A.P. Biosensor for detection of bacteria with probiotic potential and food pathogens. Letters in Applied NanoBioScience 2020, 9, 800-807, https://doi.org/10.33263/LIANBS91.800807. 